\title{
Publisher's Note: Förster-type triplet-polaron quenching in disordered organic semiconductors [Phys. Rev. B 96, 184203 (2017)]
}

R. Coehoorn, P. A. Bobbert, and H. van Eersel (Received 21 November 2017; published 27 November 2017)

DOI: 10.1103/PhysRevB.96.179904

This paper was published online on 15 November 2017 with an omission of an inset in Fig. 8. The figure has been corrected as of 20 November 2017. The figure is correct in the printed version of the journal. 